\title{
Experimental ulcerative herpetic keratitis. IV. Preliminary observations on the efficacy of a herpes simplex subunit vaccine
}

\author{
C. A. CARTER,${ }^{1}$ C. E. HARTLEY,${ }^{2}$ G. R. B. SKINNER,${ }^{2}$ S. P. TURNER,${ }^{2}$ \\ AND D. L. EASTY ${ }^{3}$ \\ From the 'Department of Surgery, the Medical School, University of Bristol; \\ ${ }^{2}$ Department of Medical Microbiology, the Medical School, University of Birmingham; and \\ ${ }^{3}$ Bristol Eye Hospital, Lower Maudlin Street, Bristol BS1 2LE
}

SUMMARY Systemic vaccination of rabbits with an inactivated type 1 virus subunit vaccine induced humoral and cell-mediated immune responses. Following ocular infection with type 1 herpes virus corneal ulceration and virus excretion were reduced in the vaccinated rabbits.

There has been a recent resurgence of interest in the prevention of herpes simplex virus (HSV) infections by vaccination, and a number of inactivated vaccine preparations have been shown to have protective efficacy not only against primary type 1 (HSV-1) infections in mice and rabbits ${ }^{1-3}$ but also against the establishment of latent ganglionic infection in these animal species. ${ }^{45}$ Protection against herpetic keratitis and reduced severity of disease have been shown in rabbits following systemic administration of live virus $^{6}$ or topical application or local injection of inactivated virus preparations. ${ }^{78}$ It seemed important therefore to determine whether a subunit inactivated vaccine which has been used towards prevention of HSV infections in human subjects ${ }^{9}$ would protect against ocular herpes simplex infection. This study investigates the immune response and degree of corneal protection against virus challenge in vaccinated and unvaccinated rabbits.

\section{Materials and methods}

Virus. Strain HFEM, a type 1 strain of herpes simplex virus $^{10}$ was used for vaccine preparation; a second type 1 strain ' $\mathrm{PH}$ ' was used for virus challenge. Viruses were titrated by the plaque method of Russell. ${ }^{11}$

Vaccine preparation. The preparative method for the inactivated subunit antigenoid vaccine Ac $\mathrm{NFU}_{\mathrm{I}}(\mathrm{S}) \mathrm{MRC}$ was followed. ${ }^{9}$ For the purpose of this study, however, the vaccine was prepared in BHK 21 cells. ${ }^{12}$

Correspondence to Mr D. L. Easty.
Immunisation schedule. $2 \mathrm{ml}$ of vaccine containing the equivalent of $4 \times 10^{7}$ cells was injected intramuscularly into each of 5 New Zealand white rabbits and the procedure repeated 3 weeks and 20 weeks later. Three untreated identical rabbits were retained as controls.

\section{IMMUNOLOGICAL METHODS}

Neutralisation tests. Sera were tested by neutralisation kinetics at a final 1/10 dilution in phosphate-buffered saline. Neutralisation rate constants ( $R$ values) were calculated for each serum as previously described. ${ }^{13}$

Immunodiffusion tests. Vaccine and antigen preparations were routinely tested in Ouchterlony immunodiffusion plates against hyperimmune antisera prepared as previously described ${ }^{14}$ Sera from vaccinated and control rabbits were tested against high quality type 1 virus antigen prepared in BHK 21 cells as previously described. ${ }^{15}$

Complement fixation tests. Complement fixation tests were carried out with overnight fixation at $4^{\circ} \mathrm{C}$ using 4 haemolytic units of complement, and $1 \%$ suspension of sensitised sheep red blood cells as an indicator system.

Lymphocyte transformation tests. The uptake of tritiated thymidine in whole blood cultures stimulated with HSV-1 cell associated antigen was assayed as previously described. ${ }^{6}$

Protection studies. The corneas of vaccinated and unvaccinated rabbits were challenged 9 weeks following the third vaccination, that is, 29 weeks following first vaccination. Corneas were infected by the microtitration method of inoculation. ${ }^{616}$ 
Fig. 1 Development of serum neutralising $(N)$, precipitating $(P)$, and complement fixing (CF) antibodies during the vaccination programme. $\oplus=$ Positive result. $\Theta=$ Negative result. $\Phi=$ equivocal result.

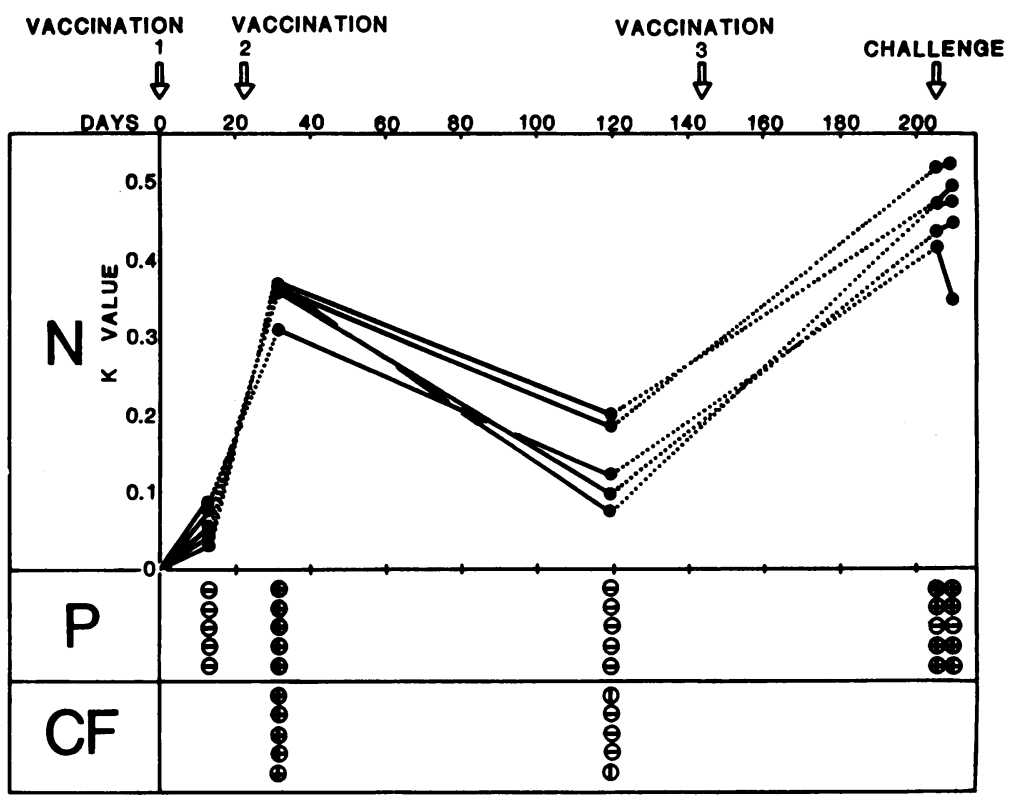

Corneal infection. The virus dose response curve and corneal infectious dose for $50 \%$ of inoculations $\left(C_{\text {ID }}\right)$ were determined for the control and for the vaccinated rabbits. ${ }^{6}$ The total area of ulcers on each cornea was measured at 2 and 4 days after challenge. ${ }^{17}$

Corneas were excised at the termination of the experiment on day 4 and the homogenised extracts from the 2 corneas of each rabbit assayed for infectious virus.

Conjunctival infection. Cytology smears from the conjunctival sacs were immediately fixed in ethanol and stained by the method of Papanicalaou and Trout. ${ }^{18}$ Specific HSV-induced cytopathic effects and nonspecific inflammatory changes were examined. ${ }^{19}$

Swabs of the upper and lower conjunctival sacs were placed in $2 \mathrm{ml}$ culture medium. The preparations were frozen and thawed, placed in an ultrasonic waterbath for $3 \mathrm{~min}$, and infectious virus titrated.

\section{Results}

IMMUNE RESPONSES

Neutralising antibody was detected in the serum of all vaccinated rabbits by 10 days after the first vaccination, with a mean $\mathrm{K}$ value of $0.06 \pm 0.01$ (SE). This rose to $0 \cdot 35 \pm 0 \cdot 0110$ days after the second vaccination, declined to a mean of $0 \cdot 13 \pm 0 \cdot 02$ over a 13 weeks period, but following a third vaccination increased again to a mean of $0.46 \pm 0.02$ by the time of corneal challenge. Precipitating and complement fixing antibodies followed a similar pattern (Fig. 1).
Lymphocyte transformation responses to HSV-1 antigens were demonstrated in the peripheral blood of all vaccinated rabbits at 10 days after the first dose of vaccine, with a mean transformation index of $17 \cdot 3 \pm 6 \cdot 4$.

\section{PROTECTION AGAINST OCULAR INFECTION}

Corneal infection. On day 2 after challenge the vaccinated rabbits were shown to be significantly more resistant to corneal HSV infection than control rabbits ( $<<0.001$, exact $2 \times 2$ test), with a $4 \cdot 8$-fold increase in CID $_{\text {so }}$ for vaccinated animals (Fig. 2). The extent of corneal ulceration was also significantly lower in vaccinated rabbits $(\mathrm{p}<0 \cdot 005$, Mann-Whitney $U$ test) (Fig. 3). Infectious virus was identified in the corneas of 3 of 5 vaccinated rabbits and in all 3 control rabbits. However, in view of the small numbers available, this difference was not statistically significant.

Conjunctival infection. Conjunctival smears were normal in both groups on the second day after challenge. By the fourth day there was evidence of inflammatory reaction in 6/6 eyes of control and 4/10 eyes of vaccinated rabbits, and there was an exact correlation between the presence of inflammatory reaction and of infectious virus in the conjunctivae at this stage.

The titres of infectious virus in conjunctival swabs were significantly lower in vaccinated than in control rabbits on both days 2 and 4 after infection $(p<0 \cdot 05)$ (Fig. 3). 


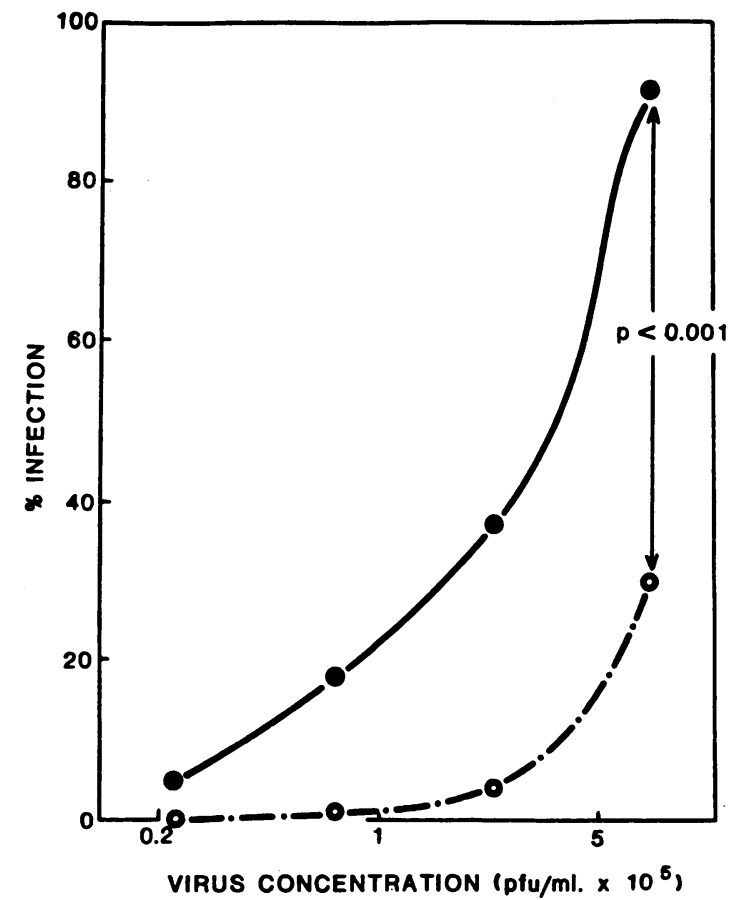

Fig. 2 Virus dose response curves for corneas of control

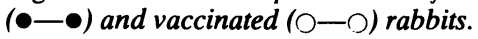

\section{Discussion}

This study has demonstrated that systemic administration of a type $1 \mathrm{HSV}$ subunit vaccine will stimulate humoral and cellular immune responses with good levels of protection against corneal challenge with live HSV-1 virus.

While humoral antibody was stimulated by one vaccination, the level of activity was almost certainly 'boosted' by a second vaccination. Thereafter, following a 3-month rest period, humoral antibody levels declined but at least in terms of neutralising antibody were rigorously stimulated by a further vaccination. This is consistent with previous studies on vaccination against both HSV and pseudorabies virus, where, although neutralising antibody clearly declined to undetectable levels by 3 months following vaccination, good levels of neutralising antibody and clear evidence of protection were apparent following challenge with live virus. ${ }^{9021}$ It appears therefore that a low or undetectable level of neutralising antibody is not inconsistent with a state of protection of vaccinated animals. To what extent the degree of protection correlates with other parameters of the immune response, for example, duration or maximum levels of antibody or cellular immune reactions following vaccination, will require more detailed
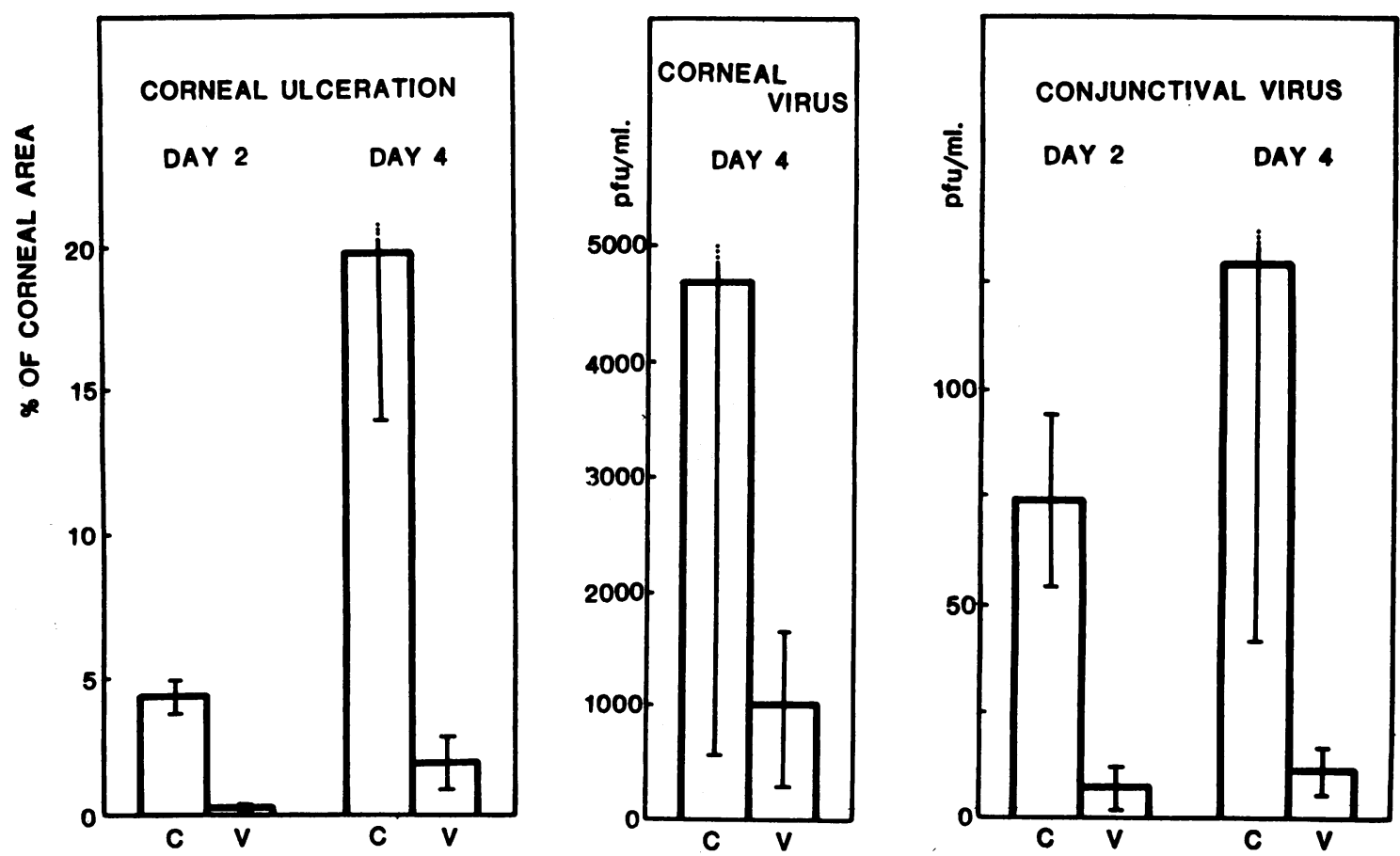

Fig. 3 Extent of herpetic corneal ulceration, and titres of infectious virus in corneal extracts and in conjunctival swab media, in control $(C)$ and vaccinated $(V)$ rabbits: mean $\pm S E$. 
investigation of the temporal changes in these responses and their relationship to protection levels.

The degree of protection against corneal HSV infection observed in the vaccinated rabbits was marked but was less great than that afforded by immunisation with live virus. ${ }^{6}$ Although 3 injections of vaccine were given, it is possible that adjustment of the schedule might enhance the efficacy of vaccination. It is apparent, of course, that protection was not complete, which accords with other vaccination protection studies in this infection. ${ }^{78}$ Indeed complete protection by immunological mechanisms in any infection transmitted by the cutaneous route may be an unobtainable goal. On the other hand it is certain that the dosage and efficiency of infection technique in our experimental ocular infections constituted a considerably more rigorous virus challenge than would be obtained in the contraction of infection per naturam. Protection of the vaccinated animals was already apparent at 2 days after corneal challenge, following a pattern similar to that observed in rabbits immunised with live virus. ${ }^{6}$ The incidence of latent ganglionic infection could not be determined in the present investigation, but it is intended to extend the experimental model to study this aspect of vaccine efficacy.

It should be remembered that the experimental model used here is one of primary, exogenous infection, and the value of the vaccine in preventing secondary exogenous infection, or in inhibiting recurrence, is as yet undetermined. However, a substantial minority of the population in developed countries exhibits no serological evidence of previous HSV infection, ${ }^{22}$ and the importance of primary HSV infections, particularly at the genital site, is becoming increasingly apparent. It may be concluded that the selective administration of the subunit vaccine used here, with the prime object of prevention of HSV disease at more frequent sites of infection, would also be expected to provide a considerable degree of protection against ulcerative herpetic keratitis.

We appreciate the help and encouragement of Professor J. H. Peacock and Dr M. O. Symes. This work was kindly supported by the Royal National Institute for the Blind and the South West Regional Health Authority.

\section{References}

1 Anderson WA, Kilbourne ED. Immunization of mice with inactivated herpes simplex virus. Proc Soc Exp Biol Med 1961; 107: 518 .
2 Kitces EN. Morahan PS. Tew JG. Murray BK. Protection from oral herpes simplex virus infection by a nucleic acid-free virus vaccine. Infect Immun 1977: 16: 955-60.

3 Walz MA. Price RW. Hayashi K. Katz BJ, Notkins AL. Effect of immunization on acute and latent infections of vaginouterine tissue with herpes simplex virus types 1 and 2. J Infect Dis 1977: 135: 744-52.

4 Asher LVS. Walz MA. Notkins AL. Effect of immunisation on the development of latent ganglionic infection in mice challenged intravaginally with herpes simplex virus types 1 and 2. Am J Obstet Gvnecol 1978: 131: 788-91.

5 McKendall RR. Efficacy of herpes simplex virus type 1 immunisation in protecting against acute and latent infection by herpes simplex virus type 2 in mice. Infect Immun 1977; 16: 717-9.

6 Carter C. Easty DL. Experimental ulcerative herpetic keratitis. I. Systemic immune responses and resistance to corneal infection. Br J Ophthalmol 1981; 65: 77-81.

7 Pollikoff $\mathbf{R}$. Topical vaccine therapy in herpetic keratitis. Lancet 1970; i: 1064.

8 Metcalf JF. Protection from experimental ocular herpetic keratitis by a heat-killed virus vaccine. Arch Ophthalmol 1980; 98: 893-6.

9 Skinner GRB. Pre-pubertal vaccination against herpes simplex virus infection towards prevention of cervical carcinoma. Blair Bell Memorial Lecture. London: Royal College of Obstetricians and Gynaecologists. 1980.

10 Geder L. Skinner GRB. Differentiation between type 1 and type 2 strains of herpes simplex virus by an indirect immunofluorescent technique. J Gen Virol 1971; 12: 179-82.

11 Russell WC. A sensitive and precise plaque assay for herpes virus. Nature 1962; 195: 1028.

12 Macpherson I. Stoker M. Polyoma transformation of hamster cell clones-an investigation of genetic factors affecting cell competence. Virology 1962; 16: 147.

13 Skinner GRB. Thouless ME, Trueman S, Edwards J, Gibbs AJ. Serological relatedness of herpes simplex viruses: type-specificity of antibody response. Immunology 1976; 31: 481-94.

14 Watson DH. Shedden WIH. Elliot A, et al. Virus specific antigens in mammalian cells infected with herpes simplex virus. Immunologv 1966; 11: 390.

15 Skinner GRB, Taylor J, Edwards J. Precipitating antibodies to herpes simplex virus in human sera; prevalence of antibody to common antigen (Band II). Intervirology 1974; 4: 320-4.

16 Jones BR, Al-Hussaini MK. Therapeutic considerations in ocular vaccinia. Trans Ophthalmol Soc UK 1963; 83: 613-31.

17 Markham RHC, Carter C. Scobie M, Metcalfe C, Easty DL. Double blind clinical trial of adenine arabinoside and idoxuridine in herpetic corneal ulcers. Trans Ophthalmol Soc UK 1977; 97: 333-40.

18 Papanicolaou G. Traut HF. The diagnosis of the uterine cancer by the vaginal smear. New York: Commonwealth Fund. 1943: 7.

19 Williams DR, Whitney JE, Harding M. Bodfish K. Skinner GRB. Cytologic evaluation of experimental type 2 herpes simplex infection in mice. Acta Cytol (Baltimore) $1978 ; 22 ; 410-6$.

20 Skinner GRB, Williams DR, Moles AW. Sargent A. Prepubertal vaccination of mice against experimental infection of the genital tract with type 2 herpes simplex virus. Arch Virol 1980; 64: 329-38.

21 Turner SP. Hartley CE, Buchan A. Skinner GRB. The preparation and efficacy of an inactivated sub-unit vaccine against pseudorabies virus infection. Res Vet Med in press.

22 Burnet FM. Williams SW. Herpes simplex: a new point of view. Med J Aust 1939; i: 637-42. 